\title{
Strategically Mediated Reflective Practice Framework In Terms of Task, Meaningful Learning, and Interaction
}

\author{
Mehdi Shokouhi \\ Department of English, Science and Research Branch, Islamic Azad University, Tehran, Iran \\ E-mail: Mehdi_shokouhi2002@yahoo.com \\ Parviz Birjandi, (Corresponding author) \\ Department of English, Science and Research Branch, Islamic Azad University, Tehran, Iran \\ E-mail: Pbirjand@yahoo.com \\ Parviz Maftoon \\ Department of English, Science and Research Branch, Islamic Azad University, Tehran, Iran \\ E-mail: pmaftoon@gmail.com
}

Received: 02-11-2016

Accepted: 08-01-2017

Advance Access Published: March 2017

Published: 01-05-2017

doi:10.7575/aiac.ijalel.v.6n.3p.101

URL: http://dx.doi.org/10.7575/aiac.ijalel.v.6n.3p.101

\begin{abstract}
It is widely accepted that reflective teaching in its purely cognitive and introspective sense cannot be responsive to the dilemmas and the problems with which teachers encounter during their teaching practice. Thus, the present study believes that the very tentative solution to this problem is introducing teacher education in general and reflective practice in particular from a sociocultural perspective where any sort of knowledge is dialogically constructed as a result of interaction among individuals. Although the shift in paradigm, i.e. moving from a cognitive position to a more situated and social epistemology in teacher education, has already been acknowledged and addressed by scholars such as Johnson (2006, 2009), Johnson and Golombek (2003), Golombek (2011), Freeman (2004), and Hawkins (2004), the current literature on teacher education reveals of no direct or serious attempt as a framework in which such a view has been put into practice in teacher education. As a result, the present study proposed a tentative framework under the rubric of 'Strategically Mediated Reflective Practice' (henceforth SMRP) framework that treats reflective practice largely as an interactive process rather than an individualistic and demonstrates how reflective practice is strategically mediated with the help of more knowledgeable others and new insights emerge resulting from dialogical thinking, highlighting the Vygotskian notion of Concept development. More importantly, examining the SMRP framework with four participants, the present study evidently reports the affirmative and constructive outcome of this framework on the utilitarian ground language teaching.
\end{abstract}

Keywords: sociocultural theory, teacher education, reflective practice, strategic mediation, concept development, internalization

\section{Introduction}

Reflective practice was originally proposed by educational philosopher John Dewey in the early twentieth century. Dewey (1933) makes a distinction between action that is routine and action that is reflective. Half a century later, Schon (1983) expands Dewey's concept of reflection. What has to be underlined is the issue that the concept of teachers as reflective practitioners is clearly a vast improvement over the limited and limiting concept of teachers as passive technicians, where teachers have to submit themselves to the principles of methods. However, reflective teaching is not without its shortcoming.

In general, reflective movement has been severely criticized for introducing reflection and reflective practice as an introspective process. Solomon (1987) makes a powerful case for reflection as a social practice, in which the articulation of ideas to others is central to the development of a critical perspective. According to Day (1993) Reflective movement has also been criticized for its lack of attention to the discursive or dialogical dimension of teacher learning. Moreover, Zeichner and Liston (1996) believe that reflective movement has portrayed reflection as largely a solitary and individualistic process involving a teacher and her situation and not as an interactive process. Finally, Kumaravadivelu (2003) stresses that by focusing on the role of the teacher and the teacher alone, the reflective movement tends to treat reflection as an introspective process involving a teacher and his or her reflective capacity, and not as an interactive process. Additionally, the consequence of such a shortcoming has also been highlighted eloquently by Valli (1997) stating that 
If left unsocialized, individual reflection can close in on itself, producing detached, idiosyncratic teachers. Because reflection is not an end in itself, but for the purpose of action, communal dialogue is essential. Many different voices are necessary. (p. 86)

Elsewhere, Lortie (1975) refers to teaching as the egg carton profession because the walls of classrooms become boundaries that separate teachers as they each occupy their own insulated niche. Consequently, engaging reflective practice aiming at teacher development in such isolation can lead to what Wells (1994) has called "the loneliness of the long-distance reflector" (p. 11). The message that all of the criticisms mentioned previously want to get across is the issue that reflective teaching in its purely cognitive and introspective sense cannot be responsive to the dilemmas and the problems with which teachers encounter during their teaching practice. The present study hypothesizes that the very tentative solution to this problem, that is the treatment of reflective practice as an individualistic and introspective process, is introducing reflective practice from a sociocultural perspective, where any sort of knowledge is dialogically constructed as a result of interaction among individuals.

As a result, the present study tends to propose a framework under the rubric of SMRP framework, not only to treat reflective practice largely as an interactive process rather than an individualistic one but also to show how reflective practice is strategically mediated with the help of more knowledgeable others and how new insights and understanding emerge as a result of dialogical thinking highlighting the Vygotskian notion of Concept development. More importantly, examining the SMRP framework as a teacher education program, the present study reports the affirmative and constructive outcome of this framework.

\section{Teacher Education from a Sociocultural Perspective}

From a sociocultural perspective, a reflective practice is not simply a solitary, mental endeavor. Rogoff (2003) reminds us that individual development constitutes and is constituted by the activities and practices of one's sociocultural context. "Thus, individual and cultural processes are mutually constituting rather than defined separately from each other. Reflective practice that neither isolates nor obscures individual teacher growth, but places it in the sociocultural context of the school community has promise for promoting and sustaining the work of teachers (Zeichner \& Liston, 1996).

According to Johnson (2009), from a sociocultural perspective, teacher cognition "originates in and is fundamentally shaped by the specific social activities in which teachers engage" (p. 17). Johnson (2009) believes that one way by which we can trace teacher cognitive development is by investigating how mediation develops. Johnson claims that such an investigation is best captured through Vygotskian concept of zone of proximal development. She rationalizes her claim by giving a description of ZPD from Lantolf (2000) as "a metaphor for observing and understanding how mediational means are appropriated and internalized" (p.17).

Additionally, According to Johnson and Golombek (2003), teacher education form a sociocultural perspective enables teacher educators to see how various tools work to create a mediational space in which teachers can externalize their current understandings and then reconceptualize and recontextualize their understandings and develop new ways of engaging in the activities associated with teaching.

This shift in paradigm, i.e. moving from a cognitive position to a more situated and social epistemology in teacher education, has already been acknowledged and addressed by scholars such as Johnson (2006, 2009), Johnson and Golombek (2003), Golombek (2011), Freeman (2004), and Hawkins (2004) . Johnson (2006) writes that learning to teach from a sociocultural perspective is based on the assumption that knowing, thinking, and understanding come from participating in the social practices of learning and teaching in specific classroom and school situations.

The very basic and fundamental problem with regard to a sociocultural view of teacher education is the issue that there is no framework in which such a view is put into practice. The only application of sociocultural perspective in teacher education is just showing how teacher development is also justifiable from this perspective. Thus, through the following section, the present study tends to propose framework under the rubric of SMRP framework along with a detail explanation of its underlying principles.

\section{SMRP Framework: The Underlying Principles}

\subsection{Principle of Concept Development}

The very basic issue behind SMRP framework is the issue of concept development and more specifically development of true concept. Vygotsky (1963) distinguishes between two types of concepts 1) everyday concepts, 2) scientific concepts. Vygotsky believes that the content of these concepts shape our mental activity. Everyday concepts are divided in two parts depending on their accessibility to conscious inspection: 1) spontaneous, 2) non-spontaneous. Spontaneous concepts are formed as a result of concrete practical experiences of a person as he is socialized into a culture. Attempting to bring such a concept to conscious inspection, one comes up with vague, incoherent, incomplete, and even inaccurate statement of the concept. Non-spontaneous concepts are those which are open to conscious inspection. Nonspontaneous concepts are intentionally and consciously acquired. Vygotsky (1987) argued that scientific concepts are not assimilated in ready-made or prepackaged form. Vygotsky (1987, as cited in Daniels, 2007) writes that

Pedagogical experience demonstrates that direct instruction in concepts is impossible. It is pedagogically fruitless. The teacher who attempts to uses this approach achieves nothing but a 
mindless learning of words, an empty verbalism that stimulates or imitates the presence of concepts. (p. 312)

\subsection{Principle of Psychological Tools (Development of True Concepts)}

Another significant principle behind SMRP framework is notion of Psychological Tools in which Kozulin (2003) outlines three types of information that are conveyed in educational setting as follows:

- Psychological tools (true concepts)

- Technical skills

- Content

According to Kozulin (2003), psychological tools are the most powerful because they guide our cognitive activity in many situations while technical skills are used only in activities which they were learned and the content is usually confined to a knowledge area. As Daniels (2001) states from Vygotsky's perspective the use of psychological tools:

- introduces several new functions connected with the use of the given tool and with its control;

- $\quad$ abolishes and makes unnecessary several natural processes, whose work is accomplished by the tool; and alters the course and individual features (the intensity, duration, sequence, etc.) of all the mental processes that enter into the composition of the instrumental act, replacing some functions with others.

\subsection{Principle of Internalization}

According to Lantolf (2006), internalization is the process through which members of communities of practice appropriate the symbolic artifacts used in communicative activity and convert them into psychological artifacts that mediate their mental activity. Through internalization, symbolic artifacts lose their exclusive unidirectional quality intended for social others and take on bidirectional functions intended for social others and the self.

According to Kozulin (1990), "the essential element in the formation of higher mental functions is the process of internalization" (p. 116). Vygotsky (1978) addressed internalization in the often-cited statement that every psychological function appears twice: first between people on the interpsychological plane and then within the individual on the intrapsychological plane. But perhaps the true essence of the concept of the internalization is best captured by Winegar's (1997) definition of the concept:

Internalization is a negotiated process of development that is coconstructed both intra- and interpersonally. Through this process, immediate person-environment relationships are reorganized, and some aspects of this reorganization may carry forward to contribute to future reorganization. At least for humans, this process always is socially mediated. (p. 31)

\subsection{Principle of Verbalization}

Considering the importance of concept development in teacher education, SMRP framework suggests, once the contents are presented to the teachers, they should be provided with the chance to verbalize their understanding of the contents, and teachers should receive feedback by more knowledgeable others. Such a process can be captured through the notion of verbalization. According to Gal' Perin (1992) verbalization is a process by which individuals make their own perceptions explicit to others.

According to Arievitch and Stetsenko (2000), Gal' Perin, in particular, emphasized the importance of orienting individuals to the rationality and systemic structuring of complex domains of knowledge which necessarily precedes guided exploration and practice. Additionally, they underline that Gal' Perin's theory of verbalization proposes that without a proper orienting basis, individuals are not able to plan their participation in pedagogical activities and thus their contribution to such activities as well as resultant development are not optimized.

As a result, Gal' Perin (1992) highlights, once the teachers verbalized their understanding, their perception is made explicit for dialogical mediation and based on their verbalization, it is the job of the more knowledgeable others to introduce them the scientific concepts. Introducing scientific concepts could be in the form of reading a particular article or a specific book suggested by more knowledgeable others. Then new insights and understanding should be achieved as a result of dialogical negotiation between the teachers and more knowledgeable others. Such a process should be continued to the time that evidence of true concept development is heard from the teachers. It is in this sense that the term mediated reflection comes to play a significant role.

\subsection{Principle of Mediation and Strategic Mediation}

Moreover, such mediation should be strategic in the sense that not all kinds of mediation lead into development rather based on the individuals' needs, it is the job of more knowledgeable others to provide them this strategic mediation.

Besides, one might argue that such mediation and even strategic mediation by more knowledgeable others would make individuals more dependent and less autonomous comparing with reflective practice as an individualistic and introspective process. But what should be brought into consideration is that the ones who act with the help of more knowledgeable others must not be considered weaker than those who act independently. As a matter of fact, it is absolutely the other way around from a sociocultural perspective. According to Aljaafreh and Lantolf (1994), potential level is more indicative of mental growth than actual development. 
Moreover, they underlined that individuals who are able to respond to such mediation must be considered to be at a more advanced developmental level than the ones who fail to do so, because those who responds to mediation can be expected to show a more rapid rate of actual development. Importantly, what is significant is not what a person can do on his own; but rather how far one can move forward and reach what he can potentially do. Moreover, Lantolf (2000) argues, "even in those cases in which experts and novices do come together, as in a teaching situation, novices do not merely copy experts' capabilities; rather they transform what the experts offer them as they appropriate it” (p. 17).

\subsection{An Integrated view of SMRP Framework's Underlying Principles}

Since SMRP framework is framed through a sociocultural theory and based on the notion of concept development, it has great advantages over the other frameworks in which reflective practice is largely treated as an individualistic, solitary, and introspective process. It is believed that teachers practice is largely controlled by the existing psychological tools in individuals' minds (Kozulin, 2003). Psychological tools are described as "true concepts". According to Vygotsky (1963), one way to arrive at true concepts is by providing the individuals the opportunities to investigate their "everyday concepts" in the light of the "scientific concepts". Such a process of investigation could be realized through what was proposed by Gal' Perin (1992) as "verbalization" by which individuals make their own perceptions explicit to others. Once individuals' perception is made explicit, they are open to dialogical mediation which can lead to restructuring of the individuals' perception. This also provides the teachers with psychological tools or true concepts by which they can control their activity in close association with their perception. Since the teachers develop true concepts through a mediated reflective process, the SMRP framework hypothesizes that the gap between what they believe and what they do, which is a significant concern in teacher education, would be to a great extent minimized and in some cases removed entirely.

\section{Research Purpose}

As it is the concern of many teacher education programs, this study aimed to examine to what extent SMRP framework is effective and successful in removing the gap and the mismatch between teachers' cognition (espoused theory) and teachers' practice (theory in action). To achieve the aims of this study, the following questions were formulated:

1. What is the effect of SMRP framework on removing the mismatch between teachers' cognition (espoused theory) and teachers' practice (theory in action)?

2. What is the effect of SMRP framework on helping teachers to practice their theory and theorize their practice?

3. What is teachers' attitude toward SMRP framework?

\section{Method}

\subsection{Participants}

The study was carried out with a group of four Iranian EFL teachers in an English language teaching institute in Babolsar, Mazandaran province. The group, consisting of one male and three females, was arranged and organized by the researcher as the conductor of the study.

\subsection{Research Setting}

The study was mainly carried out through the sessions which were held periodically every two weeks for a period of 6months. Every session, a topic was introduced for the sake of discussion. Once the topic was fully discussed, defined, and meticulously interpreted, individuals were given time and voice, during the session, to verbalize their thoughts by which they made their thoughts explicit to the researcher who functioned in the form of a more knowledgeable other and a mediator in the process of the study. Scrupulously analyzing the verbalized thoughts, the more knowledgeable other provided mediation in general and strategic mediation in particular with a consideration of each individual capabilities and ZPDs. Such mediation and strategic mediation was given in a variety of forms such as: introducing a book, an article, a video or a piece of performance by the more knowledgeable other.

Since this study was after highlighting the Vygotskiyan notion of concept development and consequently achieving the psychological tool, i.e. true concepts, the process was continued, as it is highly recommended by Gal'perin (1992), to the time that evidence of true concept development was heard from the teachers. It was in this sense that the term mediated reflection came to play a significant role. More importantly, when pieces of evidence of true concepts were heard from the participants, which highly grantee that individuals were equipped with the proper psychological tools, their teaching practice were observed and investigated to see, as proposed by Kozulin (2003), whether their cognitive ability which lead to their activity in the classroom was controlled by the provided true concepts and psychological tools or not. Finding practical, functional, and pragmatic pieces of evidence of true concepts in the participants teaching practice and self-consciously being aware in terms of both knowledge and the rationale behind the practice was what SMRP framework considered as its ultimate goal and tried to introduce such a framework as a means by which clarity was provided in terms of concepts and practice was guided more rationally, consciously, and fruitfully.

Before the whole research process, an interview, structured or semi-structured, was carried out with the participants to find out the areas which they might potentially have problems in their understanding and practicing their careers as language teachers. Once the interviews were done, there was a detailed investigation of the interviews to find the problematic areas which were shared by all the participants to avoid either frustration or over-learning for the other participants. 
Additionally, the topics which were selected for the sake of the discussion and practice in SMRP framework were as following:

1. The concept of task

2. Meaningful learning

3. Interaction and negotiation of meaning

The rationale behind choosing these topics was the normal misunderstanding of these topics by the majority of the teachers both at the level of theory and at the level of practice. Moreover, the topics were also selected by observation of the participants' classroom practice as well.

\subsection{Instrumentation}

Observation, interview, the participants' detailed report and analysis of their classroom practice, questionnaire, and video recording of SMRP framework's meetings were used as means of data collection in the study. The researcher observed the meetings with regard to how the group members collaborated, interacted, and engaged in conversation. The interviews were run with the participants before and after the research process. In the interview with the participants, they were asked about their experience in SMRP framework and the factors which they found supportive or constraining during the SMRP framework's meetings.

Additionally, the SMRP framework meetings were documented through video-recording. The participants were also assigned to write a weekly report of their experience with regard to attending the SMRP framework and a detailed analysis of their classroom practice based on what was covered in SMRP framework via a form designed by the researcher, which is illustrated above.

\subsection{Data Analysis}

Since the major goal of the study was to detect patterns of change in teachers' cognition resulting from participation in SMRP framework, the Qualitative Research Methodology in general and the Content Analysis Approach in particular seemed quite useful in this regard. As it is mentioned by Dornyei (2007) "unlike their preconceived counterparts, the qualitative categories used in content analysis are not predetermined but are derived inductively from the data analyzed" (p.245). Such a quality of content analysis approach made it quite pertinent to the present study's achievement which was after the patterns of change in teachers' cognition that emerged out of the data analyzed.

Additionally, participants are asked to analyze their teaching practice videos and practice, with a consideration that participants were demanded to put the topic under discussion into practice and provide detailed analysis of their classes teaching practice accordingly.Then, the researcher of the study tries to reasons whether the participants' comments and ideas are rationalized or based on the SMRP framework.Moreover, the researcher does his best to illustrate the change in teacher's cognition and also the removal of the mismatch between teacher's cognition and teacher's practice.

More importantly, the researcher shows how, by attending SMRP framework as means of teacher education, participants could arrive at "true concept" (Kozulin, 2003) and achieve consistency in their theory and practice and Praxis (Freire, 1994). Finally, the unanimous rater presents his own analysis to save and avoid the whole process of data analysis form any sense of bias and partiality. It has to be underlined that the rater of the study has the authority to accept or reject both the participants' and the researcher's opinions about the presented extracts. At the end of each topic, a general recapitulation of the main theme of each section is also presented.

\section{Results and Discussion}

\section{The Concept of Task and SMRP Framework}

\section{Task in terms of scope}

Extract 1

Following our meeting, I tried to design a task to teach the grammar and I introduced the ways to break the ice. First, I tried to ask questions to make them to produce some sentences using present perfect tense. They were asked how they would break the ice if they had a new teacher ( $\left.\min 16^{\prime}: 20^{\prime \prime}\right)$. One of the students tried to make a question to break the ice, using present perfect tense. As her focus is on making question, I start the conversation with a new teacher, it is a task and the goal is to make the question, so it's meaning-focused. (Task, scope, language user, incidental learning, meaning-focused)

\section{Extract 2}

By asking a question, I tried to make a discussion to talk about different ways of breaking the ice. The students try to talk about what they really do when they want to have small talk. It can be a task because the students are language users. They use language to answer the question. The learning is incidental. (Track 2, min $\left.5^{\prime}: 47^{\prime \prime}\right)$ (Task, scope, language user, incidental learning, meaning-focused)

\section{Extract 3}

By giving a summary of last session's reading, they use their own words to say everything they comprehend. They are language users, and the learning is incidental. The focus is not on form. The meaning is concerned. (Track 1, min 16':23")(Task, incidental learning, focus on meaning) 


\section{Extract 4}

The students say their prediction about the future of their cities using future tense with "will" and comparative adjectives. It's focused on meaning. Students are language users. The outcome matches to the goal. It's authentic. The task is concerned with their listening skill. (Track 2, min 12':45") (Task, scope, language user, incidental learning, meaning-focused)

\section{Extract 5}

At the beginning of the first track, the question is asked to compare today's cities and cities in future. It's meaning-focused and students try to express their ideas but in fact, they use future tense with "will" and use comparative adjectives. (Task, scope, language user, incidental learning, meaning-focused)

\section{Extract 6}

Asking students to come to the board to involve them in class activities and asking them to answer the questions "where is Ali? He is between Reza and ....... Teaching "in front of, behind, next to, between". But I know it is not a task. (Task, scope, meaning-focused)

\section{Extract 7}

Asking students about what they do in September or ... or "What do they do on Arbor's Day, Mother's Day...?". They tried to convey their meaning in any way. (Task, scope, meaning-focused)

\section{The researcher's analysis}

Drawing on Widdowson (1998), the essential elements of a task in terms of scope can be rightfully summarized as following:

- The primary focus is on meaning rather than structure

- The focus is on pragmatic meaning rather than semantic meaning

- Students are considered as language users rather than language learners

- The process of learning is incidental rather than intentional

As illustrated above, in extract 1, the participants clearly states that "As her focus is on making question, I start the conversation with a new teacher, it is a task and the goal is to make the question, so it's meaning-focused" and also in extract 2, she adds that "It can be a task because the students are language users. They use language to answer the question. The learning is incidental". These two shows that the participant has a clear idea of the scope of the task.

Additionally, the video of her classroom practice approves the realization of her ideas on the utilitarian ground. Moreover, in extract 3, the participant clearly states that the focus is not on form and her students are language users and they are involved in the process of incidental learning which shows the participant's awareness that in task-based language teaching the focus is not on form and the significance of incidental learning which consequently posits students as language users.

In extract 4, the participant expresses that her task is meaning-focused "but in fact, they use future tense with "will" and use comparative adjectives" which shows that the participant well understood the definition of a focused task as tasks that are primarily meaning-focused with preselected grammatical feature. The same issue matches for extract 5 , extract 6 , and extract 7 in that the other participant puts her emphasis on the significance of meaning rather than form in taskbased language teaching.

\section{The rater's analysis}

Watching the video performance, the rater of the study approves both the participant's practice and the researcher's analysis with regard to extracts in extract 1, extract 2, extract 3, and extract 4. However, he rejects both the participant's practice and the researcher's analysis with regard to extract 5, extract 6 , and extract 7 since he believes other preliminary necessities of task-based language teaching in terms of scope such as pragmatic meaning, incidental learning and students as language users are not attained. He also adds that simply being meaning focused is necessary but not sufficient for a mechanism to be called task.

\section{Task in terms of authenticity}

Extract 8

At the beginning of the class, I asked one of my colleagues to come to the class to see how the students break the ice and have a small talk with her. It can be a task as it is situationally authentic. The goal is a clear output of having small talk. It focuses on speaking skill. The learners are language users. (Task, authenticity, clear outcome)

\section{Extract 9}

This discussion can be as a warm-up for the conversation practice that is followed by this task. The learners' attention is focused on meaning. The students try to make a real conversation in their book. It can be authentic because they talk about real cities, real places, etc. (Track 2, min 8':50") (Task, authenticity, focus on meaning) 


\section{Extract 10}

Introducing words (uncle and aunt) and relate them to students real family to help them understand the words better (task, authenticity)

\section{Extract 11}

Asking some questions and relate them to their real life "what's in your bedroom?" to understand the concept better (task, authenticity)

\section{Extract 12}

Motivating students to make some works with cardboards to help them get the idea of some concrete words better. Then asking some questions based on it. Involving students to make more authentic language. (task, authenticity)

\section{Extract 13}

The teacher asked some questions about Norouz and put the students in that context to have a kind of interaction in the class to make authentic language. "What do you buy?", "What do you eat?", "Do you clean your room?" (Task, situational authenticity)

\section{The researcher's analysis}

According to Ellis (2003), tasks are considered authentic in two ways. They should have either situational or interactional authenticity. It seems that the participants have properly understood the notion of authenticity as relating them to real word objects to attain either of the two previously mentioned types of authenticity. In extract 8 , the participant focuses on small talk which has the criteria of being interactionally authentic. In extract 9, the participants underlines that she is trying to help her students to make real conversation in the class which can be considered as an act toward situational authenticity.

In extract 11, the participant asks about the real objects of a room which the reality of the idea gives the task situational authenticity. The same is true for extract 13 in which the participant talks about the Nowrooz event which has the criteria of both situational and interactional authenticity. In contrast, in extract 10 and extract 12, the participant shows mistaking authenticity as simple reality. These two folders show that the participant does not have clear understanding of the notion of authenticity in her practice.

\section{The rater's analysis}

Watching the video performance, the rater of the study approves both the participant's practice and the researcher's analysis with regard to extracts $8,9,11$, and 13 . The raters of the study also approves the researcher's analysis in extract 10 and extract 12, and rejects the participant's both opinion and practice with regard to aforementioned folders.

\section{Task in terms of cognitive processes}

\section{Extract 14}

Extracting example of the unit topic from students to involve them in class work and constructing a mental image and presupposition that involve their cognitive processes (task, cognitive processes)

\section{Extract 15}

Teaching new words by describing an imaginary situation to activate students' mind to guess the meaning (task, cognitive processes)

\section{The researcher's analysis}

According to Prabhu's (1987) and Robinson (2001), a task is a mechanism in which at least one or more cognitive processes are involved based on the desired level of difficulty. Extract 14 and extract 15, with a focus of "mental image" and "imaginary situation" respectively are clearly indicative of the point that the participant is apparently and evidently aware the mental role of students' mind in task-based language teaching.

\section{The rater's analysis}

Watching the video performance, the rater of the study approves both the participant's practice and the researcher's analysis in view of the fact that he believes "mental image" and "imaginary situation" enhance the level of the difficulty of the task which is used in task-grading

\section{Meaningful Learning and SMRP Framework}

Meaningful learning in terms of subsumption, accommodation, assimilation, systematic forgetting

\section{Extract 16}

At the beginning of the first track, the students with passive voice, but they don't know how to use by-phrase. The teacher tries to activate their schemata for the passive voice. 


\section{Extract 17}

Track 1, min 12':36"= the teacher introduces by-phrase. By activating their previous knowledge about passive voices, the new information (by-phrase) is assimilated by the learners in their mind.

\section{Extract 18}

Track 2 , min $2^{\prime}: 27^{\prime \prime}=$ the teacher tries to define the meaning of a new word by giving an example of a dog that's familiar to them, then introduces the new word; tame.

\section{Extract 19}

The teacher tries to have a warm-up before reading section. Reviewing and warm-up can lead students to assimilate all the new information.

\section{Extract 20}

Track 2, min 16':43"= the real condition in the future is introduced. Before that, the students tried to use conditional sentences but they had errors. Both of the processes of assimilation and accommodation may occur in the mind of learners.

\section{Extract 21}

Track 1 = at the beginning of the class, the teacher tries to have a warm-up for reading in order to make students ready for the story about Cristopher Colombus. It can help students to stimulate the new information. Then through the reading, the teacher provides examples, definition or explanation for the new information that the students haven't faced. It leads to the process of accommodation. By asking for the main idea of each paragraph, the teacher pushes the students to say everything they understand. It may result in systematic forgetting.

\section{Extract 22}

Track 2, min 5':24" = the teacher provides examples to introduce models of prohibition that students haven't known before. It may result in accommodation.

\section{The researcher's analysis}

According to Ausubel $(1960,1963)$, meaningful learning which is opposed to rote learning subsumes new information into existing structures and memory systems, and the resulting associative links create stronger retention.

Extract 16, 17, and 18 show that the participant is trying to make the process of subsumption available by activating the relevant schemata, in this case a passive one. She also adds that "By activating their previous knowledge about passive voices", the new information is assimilated in mind of her students.

Moreover, extract 19 and 20 is also indicative of the conceptual clarity of the participant with regard to the notion of meaningful learning in that the participant starts with a "Reviewing and warm-up can lead students to assimilate all the new information" and she continues with both processes of accommodation and assimilation since she believes both "may occur in the mind of learners. For some of them, it's totally new information that they haven't had before. For others, they only need to assimilate the new information."

Finally, in extracts 21 and 22, the participant shows her vigilance with regard to another significant element in meaningful learning i.e., systematic forgetting in that continuing with the process of accommodation, she pushes her students to verbalize what they understood and she believes such activity would help the final process of meaningful learning, which is systematic forgetting. This extract illustrates that the participant has a clear idea of meaningful learning both at conceptual and practical level.

\section{The rater's analysis}

Watching the video performance, the rater of the study approves both the participant's practice and the researcher's analysis with regard to extracts $16,17,18,19,20,21$, and 22 in view of the fact that he believes what the participant has in her mind is quite clear with regard to the proper meaning of meaningful learning. He also adds that such clarity is apparent in the participant's teaching practice as well.

\section{Meaningful learning in terms of advance organizers}

\section{Extract 23}

Sometimes it was hard to give the word definition in English, like the word "Independence Day". It was better to give the Persian equivalent and relating it to our own experience "Bahman the $22^{\text {nd" }}$ or the definition of "Arbor's Day" = "Esfand the 15 $5^{\text {th" }}$ (Meaningful learning, use of prior knowledge)

\section{Extract 24}

I tried to connect unit subjects to students' own experiences and background knowledge to understand the context as much as possible. E.g., what do you do in Esfand? (Meaningful learning, use of prior knowledge) 


\section{Extract 25}

The teacher charged students' former information to help them connect the new idea to their background knowledge. Without looking for any reward the students are eager to participate in the conversation (Meaningful learning, use of prior knowledge)

\section{Extract 26}

By asking some questions about the article the teacher helped the students put their former information in action to connect to the new information they were receiving. She asked about film industry and Bollywood, which by answering, the students were involved in the issue they were supposed to learn.(Meaningful learning, use of prior knowledge)

\section{Extract 27}

Before we start to listen to the song, the teacher build the context for them to make their minds ready and have a general image about what they are listening. Asking students to make sentences with the new words of the lesson (Meaningful learning, use of prior knowledge)

\section{The researcher's analysis}

According to Ausubel (1978), another way which the mechanisms of meaningful learning such as subsumption, accommodation, assimilation and systematic forgetting, can be recognized is the use of the prior knowledge via advance organizers. Either such knowledge already exists in the mind of the participants or the teacher has to construct it to further completion of the process of meaningful learning.

Extracts 23, 24, 25, and 26 are good examples in which the participant made use of the existing prior knowledge to make association with the new information as extract 23 would be the case of "Independence day" and " $22^{\text {nd }}$ of Bahman", for extracts 24 and 25 would be students' own experiences and former knowledge respectively. Finally, it is extract 26 in which the participant tries to "put their former information in action to connect to the new information they were receiving".

On the other hand, extract 27 is indicative of the process in which the prior knowledge does not exist; however the participant is quite aware to pay careful attention to build one in that she clearly states "the teacher build the context for them to make their minds ready and have a general image about what they are listening".

\section{The rater's analysis}

Watching the video performance, the rater of the study approves both the participant's practice and the researcher's analysis with regard to extracts $23,24,25,26$, and 27 in the view of the fact that he believes the participants have a clear understanding of meaningful learning in terms of subsumption, accommodation, assimilation, systematic forgetting, and the use of prior of knowledge. He also adds that the participants not only have acquired the real essence and gist of meaningful learning, but also put them in to good practice on utilitarian ground of classroom context.

\section{Interaction and Negotiation of meaning and SMRP Framework}

\section{Interaction and negotiation of meaning in terms of input modification and simplification}

\section{Extract 28}

Defining the word "especial" by simplifying it into the word "very good" (Interaction, negotiation of meaning, simplified input)

\section{Extract 29}

The teacher tried to use simplification to give simple definition for word meanings: grocery store = supermarket. (Interaction, negotiation of meaning, input modification)

Extract 30

Using simplification to give word meanings: rest $=$ relax. (Interaction, negotiation of meaning, input modification)

\section{Extract 31}

Using simplification to teach them word meanings for example, meet=see (Interaction, negotiation of meaning, simplified input)

\section{Extract 32}

Teaching the words "chalk" and "hopping" with gestures and providing concrete examples (Interaction, negotiation of meaning, interactionally modified input)

\section{Extract 33}

Providing simple example for students to understand the more difficult ones. Simplification. (Interaction, negotiation of meaning, modified input) 


\section{Extract 34}

Teaching the words: always, never, sometimes, and providing them examples to understand the idea better. I always eat ice cream in summer. I never ski in summer. Then, after some more examples, the students made some examples (Interaction, input negotiation, input modification)

\section{Extract 35}

Asking some comprehension questions: "What is between January and March?" to trigger them analyze the month in their mind to reach the correct answer (Interaction, negotiation of meaning, interactionally modified input)

\section{The researcher's analysis}

According to Long $(1985 ; 1996)$, "Interaction and negotiation of meaning", input modification and simplification are significant elements of language instruction in any classrooms.

Extracts 28, 29, 30, and 31 are indicative of the fact that the participants are consciously aware of this issue in the view of the fact that such modification and simplification is provided via appropriate synonyms.

Moreover, extracts 32, 33, 34, and 35 also support this awareness in a similar vein in that the participants provide the modification and simplification via proper examples and in some cases concrete examples.

\section{The rater's analysis}

Watching the video performance, the rater of the study approves both the participant's practice and the researcher's analysis with regard to extracts $28,29,30,31,32,33,34$, and 35 since he also confirms that the existing modification and simplification in the classroom are interactionally modified input, which according to the Interaction Hypothesis would be very beneficial with regard to the process of language acquisition (Long, 1985).

\section{Interaction and negotiation of meaning in terms of input, intake, and output}

\section{Extract 36}

Playing games to teach them the meaning of the prepositions (in, on, under) and providing pushed output to force them make sentences with the new words (Interaction, negotiation of meaning, pushed output)

\section{Extract 37}

Involving students in class interaction by asking and answering questions related to the preposition to change input into intake and finally output in their language use (Interaction, negotiation of meaning, input-intakeoutput)

\section{Extract 38}

The question was "what do you like to do on Fridays?" but the students answered unrelated responses. The teacher provided them the material and the necessary input to help them answer correctly (Interaction, negotiation of meaning, input-intake-output)

\section{Extract 39}

Asking the students to tell the teacher what they saw in the pictures to trigger their lexicon and remember the words they have already known. Then asking them to make sentences to describe the pictures. Sometimes teacher asked some display and directed questions to get the correct answers (Interaction, negotiation of meaning, pushed output)

\section{Extract 40}

Asking them make questions and sentences about the picture "there are six flowers" (Interaction, negotiation of meaning, pushed output, auto input)

\section{Extract 41}

Asking students to make complete sentences by giving them pushed input (Interaction, negotiation of meaning, pushed output)

\section{Extract 42}

Asking some comprehension questions from the text: Who works in a factory, hospital...? Then motivating students to ask similar questions and providing pushed input to help them make complete sentences. (Interaction, negotiation of meaning, pushed output)

\section{The researcher's analysis}

It is widely accepted that the input, intake, and output is a process via which a language feature is internalized and acquired. Extracts 36, 37, 38, 39, 40, 41, and 42 show that the participants have a clear idea of this notion as they actualized in their teaching practice in that in all the mentioned folders, they conscientiously aim at pushed output, which is significantly necessary for students to pick up a language (Swain, 1995) 


\section{The rater's analysis}

Watching the video performance, the rater of the study approves both the participant's practice and the researcher's analysis with regard to extracts $36,37,38,39,40,41$, and 42 because he believes what is mentioned by the researcher's analysis "conscientiously aim at pushed output" is quite visible in the participants" practice. He also adds that the participants' awareness of the notion of the pushed-output leads to longer rate of interaction in the class, which is also beneficial for language learners.

\section{Teacher's Attitude toward SMRP Framework}

\section{SMRP framework in terms of usefulness}

\section{Extract 43}

For example, those parts which were about "teaching conversation with the purpose of meaning" were very useful to me as well as the other parts.

\section{Extract 44}

If the meetings had no effects, I wouldn't have come from session one.

\section{Extract 45}

The effect of SMRP is irrefutable. As a teacher, I used different strategies or techniques in my classes, but after attending to SMRP, I used them more consciously.

\section{Extract 46}

It's hard to say to what extent SMRP made changes in my teaching practice, but there is no doubt it made development and made me more conscious about what I do in my classes, specifically about those subjects that were discussed in SMRP meetings.

\section{Extract 47}

I became aware of the related theories and the rationale behind every teaching method in my teaching process that I didn't notice before.

\section{Extract 48}

It made us conscious about our work. Sometimes many questions raised in our mind that pushed us towards the studying and thinking about the issue.

\section{Extract 49}

It definitely has influenced on choosing the necessary teaching techniques. Entering to class prepared to handle any upcoming problem gives me a sense of accomplishment in my teaching process.

What it worth to be noted in the above extracts is the issue that has been a matter of challenge in the most of the studies carried out around the subject of reflective groups in L2 teacher education, i.e. "several group members left the group, feeling that their personal needs were not met" (Key, 2006, p. 14). As you see in the above extracts, the participants express their satisfaction noting that the issues discussed in SMRP framework were relevant to theier needs at the time. One of the participants also adds that the only reason that motivated her to participate was the SMRP framework's influence on her job and the distinguishing factor regarding the influence of SMRP framework was that it matched her needs.

In another case one of the participants highlights that SMRP framework made her more conscious of her teaching practice and also helped her to become aware of the rationale behind her teaching practice. Moreover, the participants add that SMRP framework made them more conscious of their work in that it was quite effective with regard to use of teaching techniques and strategies.

\section{SMRP framework in terms of reflection}

\section{Extract 50}

I remember when I took part in these sessions, and when I wanted to go to my classes in the institute, I tried hard to put into practice whatever I learnt.

\section{Extract 51}

I think I have a better understanding of my work. Whatever I do, I ask myself "why". I'm more satisfied of what I do in my classes.

\section{Extract 52}

After attending to the SMRP and getting familiar with reflective practice, I try to think more about my works.

\section{Extract 53}

I learned some new information that I used them practically in my classes. Each meeting led me to think deeply about my work for the upcoming sessions. Sharing and using my colleagues experience was useful. 


\section{Extract 54}

It [SMRP framework] made me reflect on every minute teaching method which is applied in my classes to build the atmosphere as productive as possible.

In the section "what does it mean to be a reflective educator?" York-Barr et al. (2006), by quoting from Clarke (1995), defined reflective educators as those that "are decision makers who develop thoughtful plans to move new understandings into action so that meaningful improvements result for students" (p.10). As you see in the above extract, the participant says that she tried her best to turn what she had learned in SMRP framework into action during the class time and her teaching practice. She also adds "Whatever I do, I ask myself "why". Additionally, it is highlighted that SMRP framework made the participants, trying to achieve better productivity, think deeply and reflect on every minute of teaching method used in their classes.

\section{SMRP framework in terms of professional and collegial relationships}

\section{Extract 55}

The group made me to be more self-confident in the first place and this caused me to have a better relation with my colleagues, classmates and my friends both in the institute and university.

\section{Extract 56}

Yes it has. I tried to convey this concept to my colleagues to enhance the quality of their teaching habits.

\section{Extract 57}

It mostly affected my relationship with the colleagues that were participated inside of SMRP framework. Everyone expressed her opinions and no one criticized the other ones.

\section{Extract 58}

During the meetings my colleagues shared their experience about the special topic. Sometimes we discussed some problems or issues raised in our classes and the researcher provided support or some explanation. All of these may lead to the reflection and consequently, professional development.

York-Barr et al. (2006) believes that one of the goals which can be gained in small group reflection is "increased professional and social support given the expanded network of collegial relationships" (p.15). As it is shown in the above extract, the participant reported that the group helped her with regard to enhancing her self-confidence which consequently led to the betterment of her interaction with other colleagues and also the people outside SMRP framework such as her classmates and friends. At the same the matter of self-confidence can be regarded as a change resulted from participating in SMRP framework.

Moreover, in another extract, one of the participants reports of her efforts to share and" to convey this concept to my colleagues to enhance the quality of their teaching habits". Additionally, she repots of her satisfaction of the stress-free atmosphere at SMRP framework, being far away from any sense of criticism. Finally, the participants welcome the support and the explanation provided by the researcher at the SMRP framework in that they believe this "may lead to the reflection and consequently, professional development."

\section{SMRP framework in terms of teacher characteristic}

\section{Extract 59}

Before attending these sessions, I think I was less patient but now I feel I am more patient. I mean if I want to do anything in the class, I am no more in a rush.

\section{Extract 60}

I'll strongly suggest her to attend to such kinds of frameworks. I'll ask her to be patient since it's a kind of long-term process and the results may occur late.

York-Barr et al. (2006) believe that a major premise of reflective practice is captured through the Chinese proverb "Sometimes you must go slow to go fast" (p.2). As you see in the above extracts, the participant considers herself to be more patient than before and commits herself not to rush with regard to taking actions. Such patience is a sign of slowing down which provides the teachers with enough time for the matter of reflection. Moreover, as it is cited in York-Barr et al. (2006), the first step in reflective practice is a "deliberate pause" which they define it as "a purposeful slowing down of life to find time for reflection" (p.6).

Finally it has to be said that the participant reports that such a change has been resulted from participating in SMRP framework. Since such a change is established in teachers' cognition as a result of participating in SMRP framework, from a sociocultural perspective it could be rationalized that the way in which human cognition develops depends on social activities in which people engage (Johnson, 2006). At the same time Flavell, Miller, \& Miller (1993, cited in Johnson \& Golombek, 2003) believe that "humans are biologically endowed with cognitive abilities, thinking and memory originate in and are fundamentally shaped by the social activities in which we participate" (p. 734). 
SMRP framework in terms of self-regulation

\section{Extract 61}

In addition to the topics discussed at the SMRP framework, I thought about many more other examples which were not discussed at the SMRP framework.

\section{Extract 62}

I analyzed this framework to find a useful technique to apply in my class. Sometimes, I altered them to match to the class level and to handle the existing problems.

Sociocultural theory distinguishes three forms of regulation; object-regulation, other-regulation, and self-regulation. Looking deeply through the above extract, we see that at the very beginning individuals' reflective practice was instigated by the issues that were discussed in detail at SMRP framework which could be regarded as object-regulation and other regulation respectively. The participant reports that she reflected upon issues which were not discussed at SMRP framework whatsoever, i.e. self-regulation since it was not instigated by any other objects (problems) and others (colleagues). She also highlights that she sometimes "altered them to match to the class level and to handle the existing problems." Moving from object/other regulation to self-regulation is a process which constitutes 'internalization'. Lantolf (2006) defines internalization as "the process through which members of communities of practice appropriate the symbolic artifacts used in communicative activity and convert them into psychological artifacts that mediate their mental activity" (p.90).

\section{Conclusion}

As it is the concern of any teacher education programs, the primary concern of this research study was to show to what extent SMRP framework is effective and successful in removing the gap and the mismatch between teachers' cognition (espoused theory) and teachers' practice (theory in action).

Therefore, the participants were asked to reason and show how their teaching in the class (practice) was informed by what they have covered in SMRP framework's meeting (theory) or how what they have covered in SMRP framework's meeting (theory) could inform their teaching in the class (practice).

It has to be concluded that the data considering the effectiveness of the SMRP framework, as a means of teacher education, in removing the gap and the mismatch between teachers' cognition (espoused theory) and teachers' practice (theory in action) with regard to examining it with 3 issues, i.e., the concept of task, meaningful learning, and interaction and negotiation of meaning, were quite conclusive in particular and in many cases irrefutable in that out of 41 extracts pointed out by the participants and analyzed by the researcher and the rater, 36 of them were indicative of the removal the gap between teacher's cognition and teacher's practice in view of the fact that the participants had clear understanding of what they were doing in the class at the level of both theory and practice. Additionally, such a harmony between the participants' theory and practice were quite palpable in what they reasoned as the rationale behind their practice and actualized the same in their practice. Below comes a general overview of the results of the research project supporting the fact that the gap between teacher's theory and practice was in many cases removed.

$\begin{array}{ccc}\begin{array}{c}\text { Extracts by } \\ \text { participants }\end{array} & \begin{array}{c}\text { Approved by the } \\ \text { researcher's } \\ \text { analysis }\end{array} & \begin{array}{c}\text { Approved by the } \\ \text { rater's analysis }\end{array}\end{array}$

Task

\begin{tabular}{llll}
\hline Scope & 7 & 7 & 4 \\
\hline Authenticity & 6 & 4 & 4 \\
\hline Cognitive processes & 2 & 2 & 2 \\
\hline Meaningful learning & & & 7 \\
\hline Subsumption, systematic forgetting & 7 & 5 & 5 \\
\hline Advance organizers & 5 & & \\
\hline $\begin{array}{l}\text { Interaction and negotiation of } \\
\text { meaning }\end{array}$ & & 8 & 8 \\
\hline Input modification & 8 & 7 & 7 \\
\hline Input-intake-output & 7 & & \\
\hline
\end{tabular}

Additionally, with regard the teachers' attitude and the efficiency of the SMRP framework, the following conclusions were drawn:

$>$ SMRP framework proved itself to be usefulness in that the participants believed it made them more conscious of their teaching practice and also helped them to become aware of the rationale behind their teaching practice. 
$>$ SMRP framework proved itself to boost and enhance reflection in the view of the fact that it made the participants think deeply and reflect on every minute of teaching method used in their classes.

$>$ SMRP framework proved itself to be efficient to improve professional and collegial relationships since it helped them convey concept to their colleagues to enhance the quality of their teaching habits.

$>$ SMRP framework proved itself to develop patience as one of the teacher characteristic for the reason that the participants consider themselves to be more patient than before and commit themselves not to rush with regard to taking actions.

$>$ SMRP framework proved itself to be efficient to help teachers to achieve the state of self-regulation because the participants reported that they reflected upon issues which were not discussed at SMRP framework whatsoever, i.e. self-regulation since it was not instigated by any other objects (problems) and others (colleagues).

\section{References}

Aljaafreh, A., \& Lantolf, J. P. (1994). Negative feedback as regulation and second language learning in the zone of proximal development. The Modern Language Journal, 78(2), 465-483.doi:10.2307/328585

Arievitch, I., \& Stetsenko, A. (2000). The quality of cultural tools and cognitive development:Gal'Perin's perspective and its implications. Human development, 43, 69-92.

Ausubel, D.P. (1960). The use of advance organizers in the learning and retention of meaningful verbal material. Journal of Educational Psychology, 51, 267-272.

Ausubel, D. (1963). The psychology of meaningful verbal learning. New York: Grune \& Stratton.

Ausubel, D. (1978). In defense of advance organizers: A reply to the critics. Review of Educational Research, 48 , 251-257.

Daniels, H. (2001). Vygotsky and pedagogy. London \& New York: Routledge \& Falmer.

Daniels, H. (2007). Pedagogy. In H. Daniels, M. Cole, \& J. V. Wertsch (Eds.), The Cambridge companion to Vygotsky (pp. 307-331). Cambridge: Cambridge University Press.

Day, C. (1993). Reflection: A necessary but not sufficient condition for professional development. British Educational Research Journal, 19(1), 83-93.doi:10.1080/0 141192930190107

Dewey, J. (1933). How we think. Chicago: Henry Regnery.

Dornyei, Z. (2007). Research methods in applied linguistics. Oxford: Oxford University Press.

Ellis, R. (2003). Task-based language teaching and learning. Oxford: Oxford University Press.

Freeman, D. (2004). Language, sociocultural theory, and L2 teacher education: Examining the technology of subject matter and the architecture of instruction. In M. R. Hawkins (Ed.), Language learning and teacher education: A sociocultural approach (pp. 169-197). Toronto: Multilingual Matters.

Freire, P. (1994). Pedagogy of hope: Reliving the pedagogy of the oppressed. New York: Continuum.

Gal'perin, P.Ya. (1992). Linguistic consciousness and some questions of the relationships between language and thought. Journal of Russian and East European Psychology, 30(4),28-49.doi:10.2753/RPO1061-0405300481

Golombek, P. R. (2011). Dynamic assessment in teacher education: Using dialogic video protocols to intervene in teacher thinking and activity. In K. E. Johnson, \& P. R. Golombek (Eds.), Research on second language teacher education: A sociocultural perspective on professional development (pp. 121-135). New York, NY: Rutledge.

Hawkins, M. R. (2004). Social apprenticeships through mediated learning in language teacher education. In M. R. Hawkins (Ed.), Language learning and teacher education: A sociocultural approach （pp.89-109). Toronto: Multilingual Matters.

Johnson, K.E. (2006). The sociocultural turn and its challenges for L2 teacher education. TESOL Quarterly, 40(1), 235257.

Johnson, K. E. (2009). Second language teacher education: A sociocultural perspective. New York: Routledge.

Johnson, K.E., \& Golombek, P. R. (2003). “Seeing” teacher learning. TESOL Quarterly, 37(4), 729-738.

Key, E. (2006). Do they make a difference? A review of research on the impact of critical friends groups. Presented at the National School Reform Faculty Research Forum.

Kozulin, A. (1990). Vygotsky's psychology: A biography of ideas. Cambridge: Harvard University Press.

Kozulin, A. (2003). Psychological tools and mediated learning. In A. Kozulin, B. Gindis, V.S. Ageyev, \& S.M. Miller (Eds.), Vygotsky's educational theory in cultural context (pp. 15-38). Cambridge: Cambridge University Press.

Kumaravadivelu, B. (1994). The postmethod condition: Emerging strategies for second/foreign language teaching. TESOL Quarterly, 28(1),2748.doi:10.2 307/3587197 
Kumaravadivelu, B. (2003). Beyond methods: Macrostrategies for language teaching. London: Yale University Press.

Lantolf, J. P. (2000). Introducing sociocultural theory. In J. P. Lantolf (Ed.), Sociocultural theory and second language learning (pp. 1-26). New York: Oxford University Press.

Lantolf, J. P. (2006). Sociocultural theory and second language learning: State of the art. Studies in Second Language Acquisition, 28, 67-109.doi:1010170S027226310606 0037

Long, M. H. (1985). Input and second language acquisition theory. In S. Gass and C. Madden (eds.), Inputand second language acquisition (pp. 377-93).Rowley, Mass: Newbury House.

Long, M. H. (1996). The role of the linguistic environment in second language acquisition. In W. C. Ritchie and T. K. Bahtia , Handbook of second language acquisition (pp. 413-68). New York: Academic Press.

Lortie, D. (1975). Schoolteacher: A sociological study. Chicago: University of Chicago Press.

Prabhu, N. S. (1987). Second language pedagogy. Oxford: Oxford University Press.

Robinson, P. (2001). Task complexity, task difficulty, and task production: Exploring interactions in a componential framework. Applied linguistics, 22, 27-57.

Rogoff, B. (2003). The cultural nature of human development. Oxford: Oxford University Press.

Schon, D. (1983). The reflective practitioner: How professionals think in action. New York: Basic Books.

Solomon, J. (1987). New thoughts on teacher education. Oxford Review of Education, 44(7), 1619.doi:10.1080/0305498870130303

Swain, M. (1995). Three functions of output in second language learning. In Cook, G. (Ed.), Principle and practice in applied linguistics: Studies in Honor of H. G. Widdowson (pp. 125-144). Oxford: Oxford University Press.

Valli, L. (1997). Listening to other voices: A description of teacher reflection in the United States. Peabody Journal of Education, 72, 68-89.doi:10.1207/s15327930pje7201_4

Vygotsky, L.S. (1963). Thought and language. Cambridge: MIT Press.

Vygotsky, L.S. (1978). Mind in society. Cambridge: Harvard University Press.

Vygotsky, L. S. (1987). Thinking and speech. The collected works of L. S. Vygotsky (Vol. 1). New York: Plenum Wells, M. (1994). The loneliness of long-distance reflector. In A. Peck \& D. E. Westgate (Eds.), Language teaching in the mirror (pp. 11-14). London: Center for Language Teaching Research.

Widdowson, H. (1998). Skills, abilities, and context of reality. Annual Review of Applied Linguistics, 18, 323-333.

York-Barr, J., Sommers, W., Ghere, G., \& Montie, J. (2006). Reflective practice to improve schools: An action guide for educators. Thousand Oaks, CA: Corwin Press.

Zeichner, J. M., \& Liston, D. P. (1996). Reflective teaching: An introduction. New Jersey: Lawrence Erlbaum Associates. 